\title{
Green Process for Impregnation of Silver Nanoparticles into Microcrystalline Cellulose and Their Antimicrobial Bionanocomposite Films
}

\author{
Singaravelu Vivekanandhan ${ }^{1,2}$, Laura Christensen ${ }^{1,2}$, Manjusri Misra ${ }^{1,2 *}$, Amar Kumar Mohanty ${ }^{1,2}$ \\ ${ }^{1}$ School of Engineering, University of Guelph, Guelph, Canada; ${ }^{2}$ Bioproducts Discovery and Development Centre, Department of \\ Plant Agriculture, University of Guelph, Guelph, Canada. \\ Email: "mmisra@uoguelph.ca
}

Received May $6^{\text {th }}, 2012$; revised June $12^{\text {th }}, 2012$; accepted June $28^{\text {th }}, 2012$

\begin{abstract}
A novel greener method to impregnate silver nanoparticles (AgNPs) into microcrystalline cellulose (MCC) by curry leaf (Murraya koenigii) extract is presented. The active reduction of silver ions by curry leaf extract was explored for the in situ impregnation AgNPs into MCC. Transmission electron microscopy (TEM) analysis of MCC coated with AgNPs showed the formation of silver particle sizes in the range of $10-25 \mathrm{~nm}$ and have a spherical shape. Further the, EDS analysis of $\mathrm{MCC} / \mathrm{Ag}$ nanocomposite confirms the formation of $\mathrm{Ag}$ structure on microcrystalline cellulose. Solvent casting of poly(lactic-acid) was used to produce composite films containing silver impregnated MCC aiming for antimicrobial applications.
\end{abstract}

Keywords: Silver Nanoparticles; Impregnation; Bioreduction; Murraya koenigii; Leaf Extract

\section{Introduction}

Silver nanoparticles (AgNPs) deposited or impregnated materials (metal, polymer, metal oxide, carbon, cellulose) have been widely investigated for their unique physicochemical properties such as optical, electrical, catalytic and anti-microbial, due to their unusual interfacial effects [1-6]. They found a wide range of applications in many fields that include optical, water treatment, sensor, medical, textile, coatings as well as energy conversion/ storage [7-13]. Among the available metal nanoparticles, silver and related materials have been utilized in many nano based commercial products for their antimicrobial property. Studies suggested that the antimicrobial performance is enhanced due to an increased surface area/reduced particle size. Hence, an intensive research effort has been made to introduce AgNPs in various materials for the effective antimicrobial properties [14,15]. Recently, nanocomposites with multifunctional properties receive more attention for their demand as packaging materials $[16,17]$. Along with antimicrobial activity additional properties such as thermal, mechanical, barrier, moisture resistance and linear thermal expansion coefficient also necessary, that will widen the opportunities for numerous commercial products $[18,19]$. With this context, development of silver nanoparticle impregnated cel-

\footnotetext{
${ }^{*}$ Corresponding author.
}

lulose fibres as the multifunctional filler (which also act as subtract for AgNPs) represent as a novel approach for the development composite films with antimicrobial activity [20-22].

Inclusion of AgNPs into natural fibres (cellulose as well as cotton) has been performed using various techniques including sonochemical [23], microwave [24], chemical reduction (using sodium borohydrate) [25] as well as bioreduction (using fungus, plant leaf extract) [26, 27]. Among them, plant leaf extract mediated biological process is found to be simple as well as cost effective that also utilize ambient conditions for the reduction reaction. Ravindra et al. reported the Neelagiri and Marrti tree leaf extracts based bioreduction process for the fabrication of antimicrobial cotton fibres with AgNPs [27]. Also, our group has first demonstrated the functionalization of carbon nanotubes with AgNPs using soy leaf and Tecoma stans extract based biological process $[3,28]$. Recently, we have reported the "green" method of synthesizing AgNPs using curry leaf (Murraya koenigii) extract [29]. The effective reduction of silver ions into AgNPs by curry leaf extract has motivated to extend the research work for the fabrication of AgNP impregnated microcrystalline cellulose (MCC) as a functional fillers. Thus the present research is aimed to impregnate AgNPs into microcrystalline cellulose using Murraya koenigii 
extract as the reducing agent at ambient conditions and extending their application into the fabrication of polylactic acid (PLA) based antimicrobial Bionanocomposite films.

\section{Experimental}

\subsection{Materials}

Curry leaves (Murraya koenigii) were obtained from East Indian Food \& Spices in Guelph, Ontario, Canada. Silver nitrate $\left(\mathrm{AgNO}_{3}\right)$ as well as microcrystalline cellulose (MCC) were purchased from Sigma Aldrich and used as received without further purification. PLA (Biomer L9000) was obtained from Biomer, Inc., Germany.

\subsection{Preparation of Curry Leaf Extract}

The curry leaf extract was prepared using $10 \mathrm{~g}$ of fresh curry leaves, which were rinsed with deionized water and cut into small pieces. The chopped leaves were boiled in $75 \mathrm{~mL}$ of deionized water for 3 minutes and allowed to cool. Further the cooled leaf broth was filtered, which yielded $50 \mathrm{~mL}$ of broth and it was stored in a refrigerator at $4^{\circ} \mathrm{C}$.

\subsection{Impregnation of AgNPs into MCC}

Curry leaf extract mediated bioreduction process for the impregnation of AgNPs into microcrystalline cellulose is schematically shown in Figure 1. First, $10 \mathrm{~g}$ of MCC was suspended in $1000 \mathrm{~mL}$ of $10^{-3} \mathrm{M}$ silver nitrate and sonicated for 10 minutes. $50 \mathrm{~mL}$ of curry leaf broth was added to the mixture and stirred for 6 hours. Curry leaf extract caused the reduction of silver ions into silver, which nucleate in to silver nanoparticles on the microcrystalline fibrils. After 6 hours the mixture was allowed to setter down and the excess reaction mixture was decanted off. The AgNP impregnated MCC was washed with deionized water and dried in an oven at $55^{\circ} \mathrm{C}$ over night.

\subsection{Characterization of the Silver Impregnated Microcrystalline Cellulose}

The bioreduction of silver nanoparticles was investigated through a Varian UV-Vis spectrophotometer (300 UV-Vis) operated between 300 and $800 \mathrm{~nm}$ with $2 \mathrm{~nm}$ resolution. Transmission electron microscopy (TEM) analysis of the as received as well as AgNP impregnated microcrystalline cellulose was performed on a LEO mo- del 912AB instrument at an accelerating voltage of $100 \mathrm{kV}$. A drop of MCC suspension was placed on carbon coated copper grids and allowing the solvent to evaporate prior to analysis. Scanning electron microscope-EDS analysis of the AgNPs impregnated MCC was performed using a Hitachi, Japan, operated at an accelerating voltage of $30 \mathrm{kV}$. The crystalline nature of the in situ impregnated AgNPs was investigated using a Rigaku Multiflex X-ray powder diffractometer employed with $\mathrm{Cu} \mathrm{K} \alpha$ radiation. The XRD pattern was recorded between $10^{\circ}$ and $80^{\circ}$ at the scanning rate of $2^{\circ}$ per minute. The dried MCC powders were loaded on the glass subtract and subjected to X-ray and the diffracted pattern was recorded. Thermal behavior of AgNPs impregnated MCC was investigated using a thermo gravimetric analyzer (TGA), Q500, TA equipments. Approximately $3 \mathrm{mg}$ of sample was heated at the rate of $20^{\circ} \mathrm{C}$ per min from room temperature to $600^{\circ} \mathrm{C}$ in nitrogen atmosphere.

\subsection{Solvent Casting of PLA/MCC Composite}

$0.5 \mathrm{~g}$ of PLA was dissolved in $20 \mathrm{~mL}$ of chloroform with gentle heating and constant stirring for 30 minutes. The dried silver coated MCC powder was added in $5 \%, 10 \%$ and $20 \% \mathrm{w} / \mathrm{w}$ concentrations to separate samples. The PLA was stirred with MCC for 24 hours to allow for dispersion. The mixture was then poured into glass Petri dishes and left to evaporate. Once the chloroform had evaporated, the plastic film was removed and collected from the Petri dish.

\subsection{Antimicrobial Testing}

The PLA/MCC samples were tested for antimicrobial properties using the Charm disk assay. An agar plate was first seeded with Bacillus stearothermophilus. Small circular pieces of the films were placed on the seeded agar and incubated. Due to the presence of indicators in the agar, microbial growth is indicated by a yellow colour

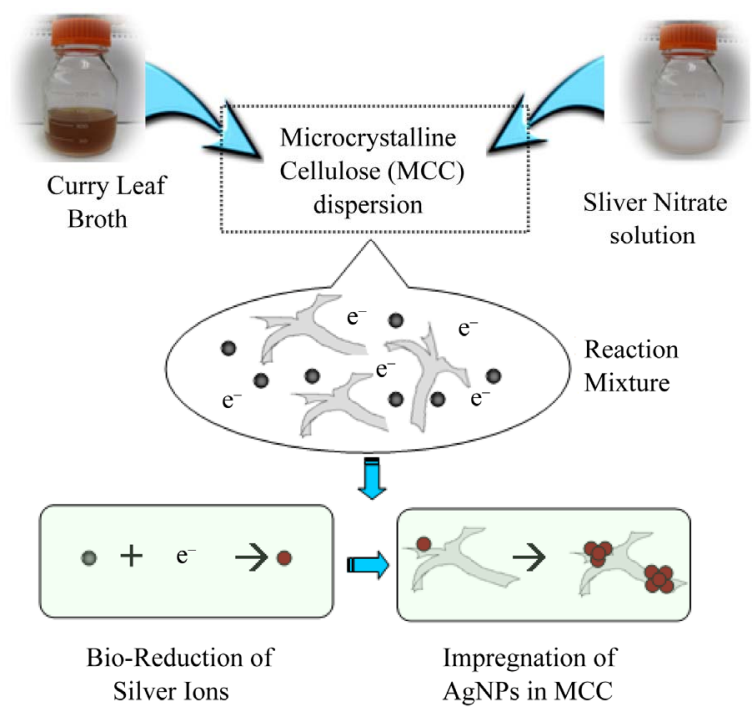

Figure 1. Schematic representation of curry leaf mediated biological process for the impregnation of AgNPs in microcrystalline cellulose. 
and inhibition of growth by a purple colour.

\section{Results and Discussion}

UV-vis spectra of reaction mixture with MCC dispersion and silver nitrate solution was recorded and compared with the spectrum of reaction mixture with curry leaf extract (after 2 hours of addition) and they are shown in Figure 2. The observed peak at $430 \mathrm{~nm}$, which is attributed to the plasmonic vibration of AgNPs, confirms the formation of AgNPs. Further it was confirmed by visual observation, TEM and XRD analysis. Figure 3 shows the photograph of as received as well as silver nanopar-

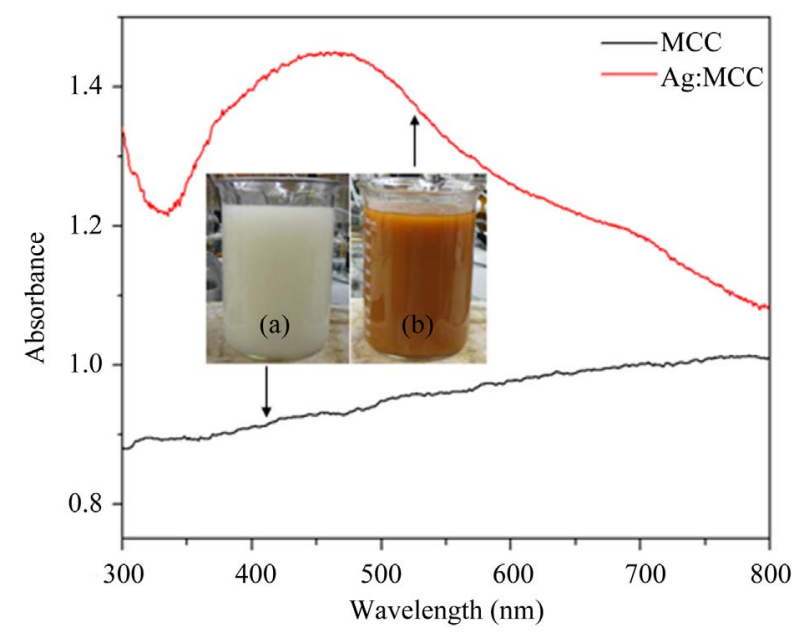

Figure 2. UV-vis spectra of the initial (a) and final (b) stages of reaction mixture (silver nitrate, microcrystalline cellulose, and curry leaf broth); Inset sows the respective photographs.
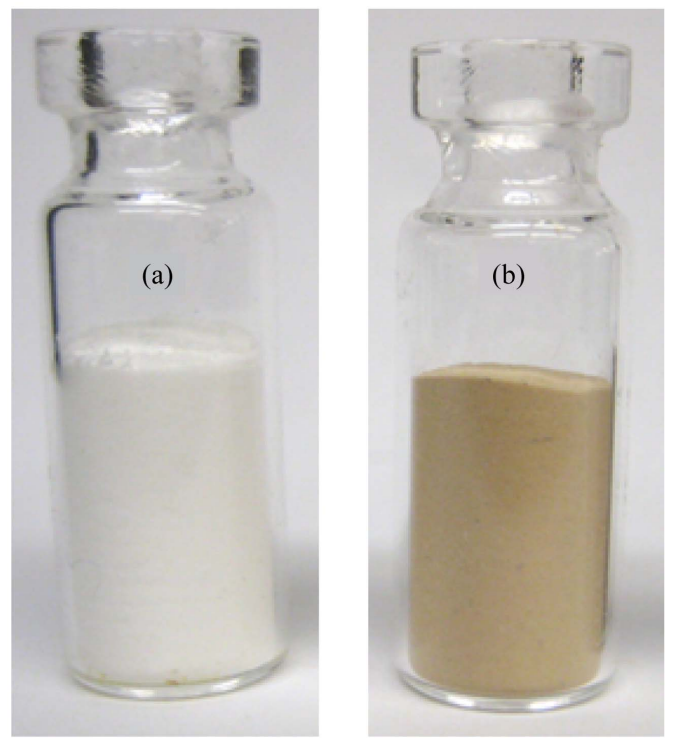

Figure 3. Photograph of microcrystalline cellulose; (a) as received and (b) AgNPs impregnated. ticle impregnated microcrystalline cellulose powder. The change in colour from white in to yellowish brown indicates the implementation of AgNPs into MCC structure using curry leaf extract mediated green process at ambient condition.

Figures 4(a)-(d) shows the transmission electron microscopic images of pristine and $\mathrm{Ag}$ nanoparticles impregnated MCC with different magnification. TEM micrographs of pristine MCC as shown in Figures 4(a) and (b) indicate the fibril structure with wide size distribution. Figures 4(c) and (d) confirms the effective impregnation of $\mathrm{Ag}$ nanoparticles into microcrystalline cellulose by curry leaf extract based bioreduction process. The impregnated AgNPs are polydisperse and ranges approximately from $10-25 \mathrm{~nm}$ with spherical shape. AgNPs were distributed among the MCC fibrils and the high tendency of particle agglomeration was observed. From this analysis it is observed that the AgNP content in some MCC fibrils are greater than others. This may be explained as the nanoparticles adsorption on MCC fibrils is strongly dependent on the physicochemical characteristics of the fibers, which indicate the necessary of physical/chemical pretreatment to the MCC fibrils.

The SEM-EDS was recorded in order to provide further confirmation on the formation of AgNPs on cellulose fibrils and also identify their approximate bulk atomic composition. SEM-EDS spectra of Ag nanoparticles impregnated MCC shown in Figure 5. The obtained EDS spectrum of $\mathrm{Ag}$ nanoparticles impregnated MCC confirms the existence of silver in the MCC and it is quantified as $\sim 1 \mathrm{wt} \%$. Further this result was supported by
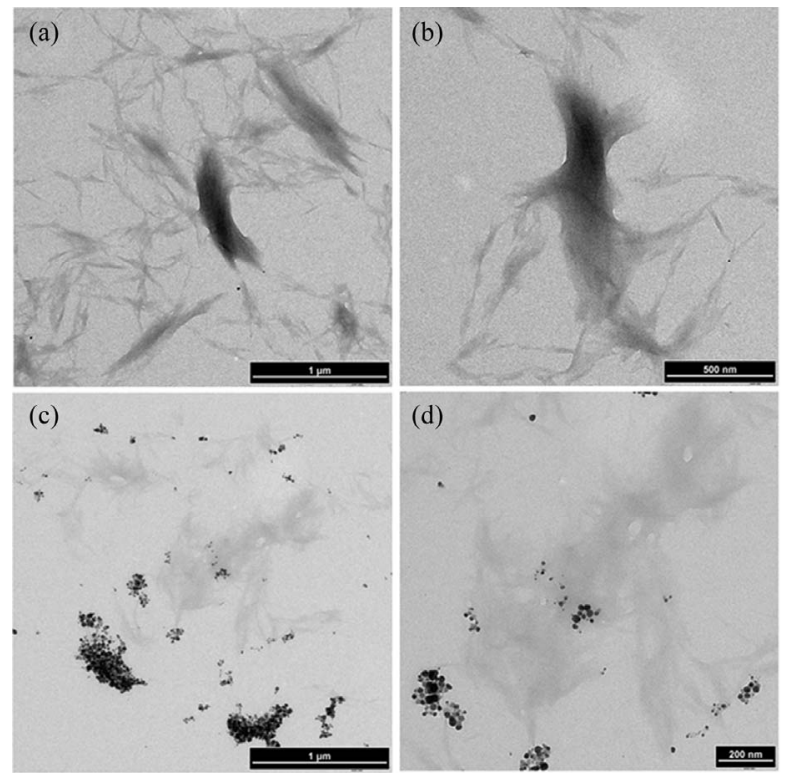

Figure 4. TEM images (with different magnifications) of microcrystalline cellulose (a), (b) control sample and (c), (d) slow addition of broth showing impregnation with AgNPs. 


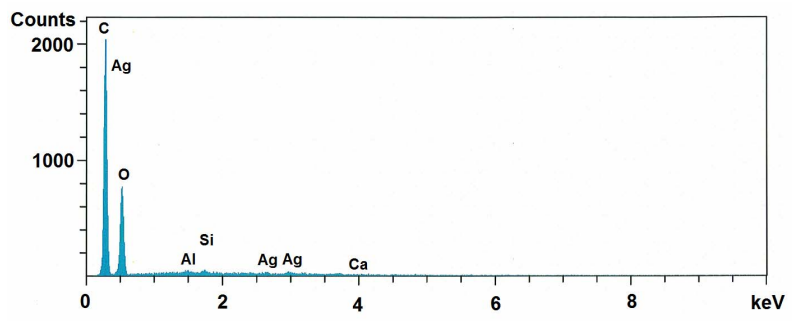

Figure 5. SEM-EDS spectra of microcrystalline cellulose impregnated with AgNPs.

TGA analysis.

Power X-ray diffraction patterns of pristine and $\mathrm{Ag}$ nanoparticles coated MCC fibrils are presented in Figure 6. The diffraction pattern for pristine MCC shows intense peak at $15^{\circ}, 16^{\circ}, 22^{\circ}, 23^{\circ}$ and $26^{\circ}$ are the characteristic peaks of cellulose fibres, which coincides with reported literature values [30]. XRD pattern for AgNPs impregnated MCC fibrils shows additional peaks at $38^{\circ}, 44^{\circ}, 64^{\circ}$ and $77^{\circ}$ which are assigned to fcc crystalline structure of silver nanocrystals. It was observed that the characteristic peaks of AgNPs have significant width, which indicates the formation of smaller Ag particles. Crystallite size of the silver nanoparticles was calculated using full width at half maximum (FWHM) of the $100 \%$ peak of silver and the Scherrer's formula,

$$
d=K \lambda /(\beta \cdot \cos \theta)
$$

where $\lambda-\mathrm{X}$-ray wavelength, $\beta-$ FWHM of the diffracttion line, $\theta$-diffraction angle, and $K$-constant, generally assumed as 0.9 . Calculated average crystallite size is $\sim 5 \mathrm{~nm}$, which indicates that the impregnated AgNPs are poly crystalline in nature thus TEM images show the particles range between 10 and $20 \mathrm{~nm}$.

Thermal behavior of pristine and AgNPs impregnated MCC fibrils were performed using TGA and the recorded thermogram is shown in Figure 7. A single step thermal degradation was observed for both the MCC and Ag-MCC fibrils between $270^{\circ} \mathrm{C}$ and $380^{\circ} \mathrm{C}$ with $\sim 95 \%$ weight loss, however the addition of AgNPs causes significant change in their degradation pattern. The reaction between AgNPs and the MCC starts at $250^{\circ} \mathrm{C}$ and caused the increased degradation rate as seen in inset derivative curve (peak at $292^{\circ} \mathrm{C}$ ). Also, the increased residual mass after the degradation for the $\mathrm{Ag}$ nanoparticles impregnated MCC fibrils about $1.37 \%$ indicates the existence of silver in residual mass. This result is comparable with the SEM-EDS analysis.

Silver impregnated MCC fibrils were further utilized for the fabrication of biodegradable composite film with PLA as polymer matrix by employing solvent casting process. The solvent casting produced fairly uniform thin, flexible films. As the MCC concentration is increased the film becomes less translucent. The samples containing the MCC + AgNPs also showed a brownish colour. The coated cellulose showed increased dispersion compared to the control sample. This may be because the silver neutralizes the surfaces charges present on the MCC which cause the aggregation. Microbial inhibition, indicated by a purple colour, was observed in all the MCC + AgNP samples (Figure 8). The 20\% MCC + AgNPs sample showed the greatest amount of inhibition. This suggests that the MCC + AgNPs/PLA composite have antimicrobial properties. However, further testing is required confirm and to better quantify this property.

\section{Conclusion}

In summary, the curry leaf extract mediated bioreduction process was successfully employed for the rapid impregnation of AgNPs into MCC at ambient conditions. TEM and XRD analysis respectively confirmed the formation of spherical AgNPs and fcc crystalline structure

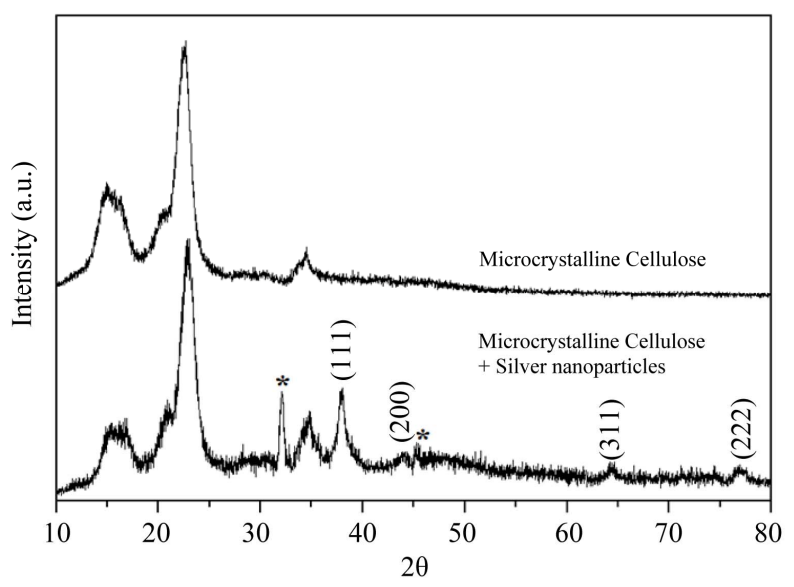

Figure 6. XRD analysis of (a) as received and (b) AgNPs impregnated microcrystalline cellulose.

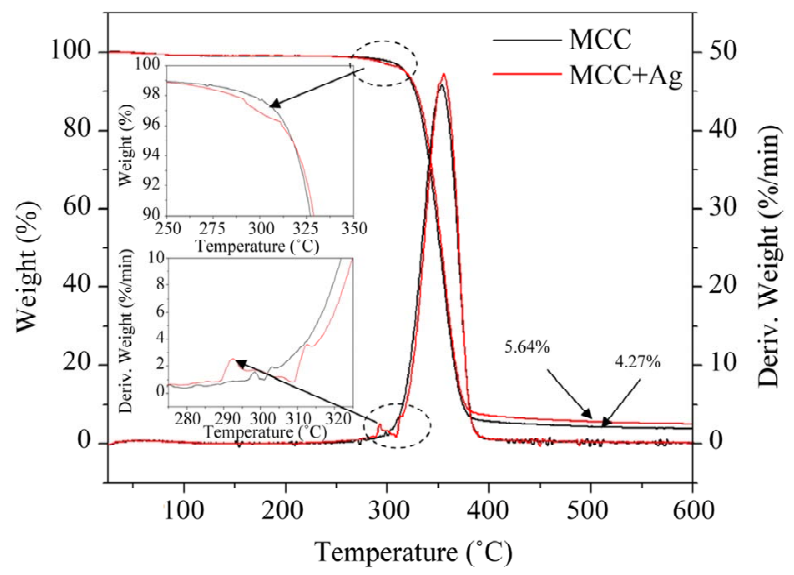

Figure 7. Thermo gravimetric (TG) analysis of (a) as received and (b) AgNPs impregnated microcrystalline cellulose. 

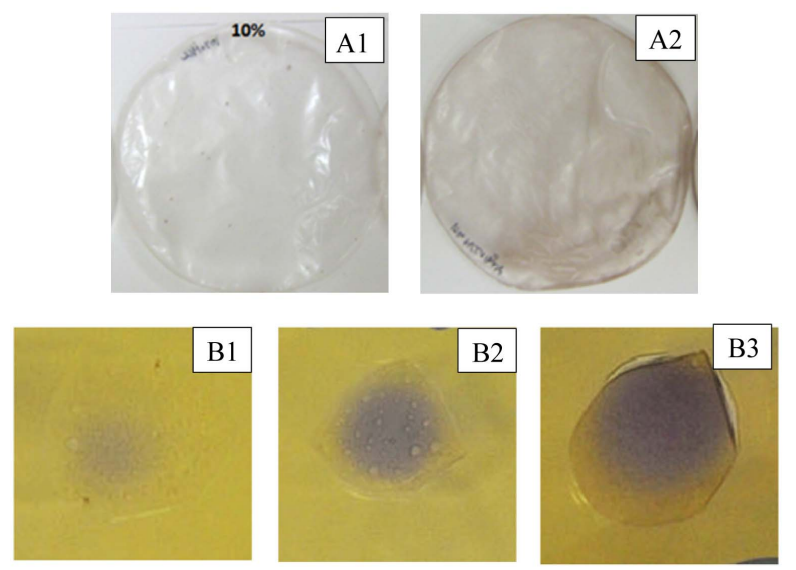

$10 \% \mathrm{MCC}+90 \% \mathrm{PLA} \quad 5 \% \mathrm{MCC}-\mathrm{Ag}+95 \% \mathrm{PLA} \quad 20 \% \mathrm{MCC}-\mathrm{Ag}+80 \% \mathrm{PLA}$

Figure 8. Photograph of MCC-PLA (A1) and MCC-AgPLA (A2) composite films as well as antimicrobial analysis of MCC-PLA (B1) and MCC-Ag-PLA (B2 and B3) composites.

with in microcrystalline cellulose, further it was supported by SEM-EDS results. AgNPs that are impregnated into MCC were estimated using TG analysis, which is found to be $\sim 1.3 \%$, which is very much consistence with SEM-EDS analysis. The fabricated silver impregnated MCC then combined with PLA to produce antimicrobial bionanocomposite film using solvent casting process. The preliminary analysis showed that these films exhibits significant antimicrobial properties and further research in this direction is in progress.

\section{Acknowledgements}

Authors are thankful to 2009, Ontario Ministry of Agriculture, Food and Rural Affairs (OMAFRA)—New Directions \& Alternative Renewable Fuels Research Program Project number SR9225, 2009 OMAFRA-University of Guelph, Bioeconomy industrial uses and NSERC NCE AUTO21 project for the financial support to carry out this research. Authors would also like to acknowledge the University of Guelph, 2009 President's Research Assistantship for providing LC's fellowship.

\section{REFERENCES}

[1] Y. W. Cao, R. Jin and C. A. Mirkin, "DNA-Modified Core-Shell Ag/Au Nanoparticles," Journal of American Chemical Society, Vol. 123, No. 32, 2001, pp. 7961-7962. doi:10.1021/ja011342n

[2] J. Gong, Q. Chen, M. R. Lian, N. C. Liu, R. G. Stevenson and F. Adami, "Micromachined Nanocrystalline Silver Doped $\mathrm{SnO}_{2} \mathrm{H}_{2} \mathrm{~S}$ Sensor," Sensors and Actuators B: Chemical, Vol. 114, No. 30, 2006, pp. 32-39. doi:10.1016/j.snb.2005.04.035

[3] S. Vivekanandhan, D. Tang, M. Misra and A. K. Mo- hanty, "Novel Glycine Max (Soybean) Leaf Extract Based Biological Process for the Functionalization of Carbon Nanotubes with Silver Nanoparticles," Nanoscience and Nanotechnology Letters, Vol. 2, No. 3, 2010, pp. 240243. doi:10.1166/nnl.2010.1087

[4] Z. H. Mbhele, M. G. Salemane, C. G. C. E. van Sittert, J. M. Nedeljkovic, V. Djokovic and A. S. Luyt, "Fabrication and Characterization of Silver-Polyvinyl Alcohol Nanocomposites," Chemistry of Materials, Vol. 15, No. 26, 2003, pp. 5019-5024. doi:10.1021/cm034505a

[5] T. A. Dankovich and D. G. Gray, "Bactericidal Paper Impregnated with Silver Nanoparticles for Point-of-Use Water Treatment," Environmental Science and Technology, Vol. 45, 2011, pp. 1992-1998.

[6] G. W. Yang, G. Y. Gao, C. Wang, C. L. Xu and H. L. Li, "Controllable Deposition of Ag Nanoparticles on Carbon Nanotubes as a Catalyst for Hydrazine Oxidation," Carbon, Vol. 46, No. 5, 2008, pp 747-752. doi:10.1016/j.carbon.2008.01.026

[7] Y. F. Wanga, J. H. Yaoa, G. Jiab and H. Leia, "Optical Prosperities of Ag-ZnO Composition Nanofilm Synthesized by Chemical Bath Deposition," Acta Physica Polonica A, Vol. 119, 2011, pp. 451-455.

[8] Y. Lv, H. Liu, Z.Wang, S. Liu, L. Hao, Y. Sang, D. Liu, J. Wang and R. I. Boughton, "Silver Nanoparticle-Decorated Porous Ceramic Composite for Water Treatment," Journal of Membrane Science, Vol. 331, No. 1-2, 2009, pp. 50-56. doi:10.1016/j.memsci.2009.01.007

[9] K. Aslan, M. Wu, J. R. Lakowicz, and C. D. Geddes, "Fluorescent Core-Shell $\mathrm{Ag} @ \mathrm{SiO}_{2}$ Nanocomposites for Metal-Enhanced Fluorescence and Single Nanoparticle Sensing Platforms," Journal of the American Chemical Society, Vol. 129, No. 6, 2007, pp. 1524-1525. doi:10.1021/ja0680820

[10] T. Maneerung, S. Tokura and R. Rujiravanit, "Impregnation of Silver Nanoparticles into Bacterial Cellulose for Antimicrobial Wound Dressing," Carbohydrate Polymers, Vol. 72, No. 1, 2008, pp. 43-51. doi:10.1016/j.carbpol.2007.07.025

[11] A. Kumar, P. K. Vemula, P. M. Ajayan and G. John, "Silver-Nanoparticle-Embedded Antimicrobial Paints Based on Vegetable Oil," Nature Materials, Vol. 7, 2008, pp. 236-241. doi:10.1038/nmat2099

[12] M. L. Gulrajani, D. Gupta, S. Periyasamy, S. G. Muthu, "Preparation and Application of Silver Nanoparticles on Silk for Imparting Antimicrobial Properties," Journal of Applied Polymer Science, Vol. 108, No. 1, 2008, pp. 614623. doi:10.1002/app.27584

[13] K. S. Park, J. T. Son, H. T. Chung, S. J. Kim, C. H. Lee, K. T. Kang and H. G. Kim, "Surface Modification by Silver Coating for Improving Electrochemical Properties of $\mathrm{LiFePO}_{4}$," Solid State Communications, Vol. 129, No. 5, 2004, pp. 311-314. doi:10.1016/j.ssc.2003.10.015

[14] M. Chen, Z. Yang, H. Wu, X. Pan, X. Xie and C. Wu, "Antimicrobial Activity and the Mechanism of Silver Nanoparticle Thermosensitive Gel," International Journal of Nanomedicine, Vol. 6, 2011, pp. 2873-2877. doi:10.2147/IJN.S23945 
[15] D. K. Božanić, S. D. Branković, N. Bibić, A. S. Luyt and V. Djoković, "Silver Nanoparticles Encapsulated in Glycogen Biopolymer: Morphology, Optical and Antimicrobial Properties," Carbohydrate Polymers, Vol. 83, No. 2, 2011, pp. 883-890. doi:10.1016/j.carbpol.2010.08.070

[16] H. M.C. de Azeredo, "Nanocomposites for Food Packaging Applications," Food Research International, Vol. 42, No. 9, 2009, pp. 1240-1253. doi:10.1016/j.foodres.2009.03.019

[17] Z. Akbari, T. Ghomashchi and S. Moghadam, "Improvement in Food Packaging Industry with Biobased Nanocomposites," International Journal of Food Engineering, Vol. 3, No. 4, 2007, pp. 1-24. doi:10.2202/1556-3758.1120

[18] K. Shameli, M. B. Ahmad, W. Z. W. Yunus, N. A. Ibrahim and M. Darroudi, "Synthesis and Characterization of Silver/Talc Nanocomposites Using the Wet Chemical Reduction Method," International Journal of Nanomedicine, Vol. 5, 2010, pp. 743-751. doi:10.2147/IJN.S13227

[19] M. A. Busoloab, P. Fernandezb, M. J. Ocioac and J. M. Lagarona, "Novel Silver-Based Nanoclay as an Antimicrobial in Polylactic Acid Food Packaging Coatings," Food Additives and Contaminants, Vol. 27, No.11, 2010, pp. 1617-1626. doi:10.1080/19440049.2010.506601

[20] Z. Chunyang, X. Jianfeng and H. Junhui, "Controlled In-Situ Synthesis of Silver Nanoparticles in Natural Cellulose Fibers toward Highly Efficient Antimicrobial Materials," Journal of Nanoscience and Nanotechnology, Vol. 9, No. 5, 2009, pp. 3067-3074. doi:10.1166/jnn.2009.212

[21] J. Kim, S. Kwon and E. Ostler, "Antimicrobial Effect of Silver-Impregnated Cellulose: Potential for Antimicrobial Therapy," Journal of Biological Engineering, Vol. 3, No. 20, 2009, pp. 1-9. doi:10.1186/1754-1611-3-20

[22] A. M. Ferraria, S. Boufi, N. Battaglini, A. M. Botelho do Rego, and M. ReiVilar, "Hybrid Systems of Silver Nanoparticles Generated on Cellulose Surfaces," Langmuir, Vol. 26, No. 3, 2010, pp. 1996-2001. doi:10.1021/la902477q

[23] I. Perelshtein, G. Applerot, N. Perkas, G. Guibert, S. Mikhailov and A. Gedanken, "Sonochemical Coating of Silver Nanoparticles on Textile Fabrics (Nylon, Polyester and Cotton) and Their Antibacterial Activity," Nanotechnology, Vol. 19, No. 24, 2008, Article ID 245705. doi:10.1088/0957-4484/19/24/245705

[24] S. M. Li, N. Jia, J. F. Zhu, M. G. Ma, F. Xu, B. Wang and R. C. Sun, "Rapid Microwave-Assisted Preparation and Characterization of Cellulose-Silver Nanocomposites" Carbohydrate Polymers, Vol. 83, No. 2, 2011, pp. 422-429. doi:10.1016/j.carbpol.2010.08.003

[25] R. J.B. Pinto, P. A. A. P. Marques, C. P. Neto, T. Trindade, S. Daina and P. Sadocco, "Antibacterial Activity of Nanocomposites of Silver and Bacterial or Vegetable Cellulosic Fibers," Acta Biomaterialia, Vol. 5, No. 6, 2009, pp. 2279-2289. doi:10.1016/j.actbio.2009.02.003

[26] N. Durán, P. D. Marcato, G. I. H. De Souza, O. L. Alves and E. Esposito, "Antibacterial Effect of Silver Nanoparticles Produced by Fungal Process on Textile Fabrics and Their Effluent Treatment," Journal of Biomedical Nanotechnology, Vol. 3, No. 2, 2007, pp. 203-208. doi:10.1166/jbn.2007.022

[27] S. Ravindra, Y. M. Mohan, N. N. Reddy and K. M. Raju, "Fabrication of Antibacterial Cotton Fibres Loaded with Silver Nanoparticles via 'Green Approach'," Colloids and Surfaces A: Physicochemical and Engineering Aspects, Vol. 367, No. 1-3, 2010, pp. 31-40. doi:10.1016/j.colsurfa.2010.06.013

[28] S. Vivekanandhan, M. Venkateswarlu, D. Carnahan, M. Misra, A. K. Mohanty and N. Satyanarayana, "Functionalization of Single-Walled Carbon Nanotubes with Silver Nanoparticles Using Tecoma stans Leaf Extract," Physica E, Vol. 44, No. 7-8, 2012, pp. 1725-1729. doi:10.1016/j.physe.2011.10.013

[29] L. Christensen, S. Vivekanandhan, M. Misra and A. K. Mohanty, "Biosynthesis of Silver Nanoparticles Using Murraya koenigii (Curry Leaf): An Investigation on the Effect of Broth Concentration in Reduction Mechanism and Particle Size," Advanced Materials Letters, Vol. 2, No. 6, 2011, pp. 429-434. doi:10.5185/amlett.2011.4256

[30] A. P. Mathew, K. Oksman and M. Sain, "Mechanical Properties of Biodegradable Composites from Poly Lactic Acid (PLA) and Microcrystalline Cellulose (MCC)," Journal of Applied Polymer Science, Vol. 97, No. 5, 2005, pp. 2014-2025. doi:10.1002/app.21779 